\title{
Desenvolvimento do sistema tegumentar em bovinos com idades gestacionais estimadas de 20 a 140 dias $^{1}$
}

\author{
Horácio Luis Tommasi Junior², Phelipe Oliveira Favaron², Rosângela Felipe \\ Rodrigues $^{2}$, Juliana Plácido Guimarães ${ }^{2}$ e Maria Angelica Miglino ${ }^{2 *}$
}

\begin{abstract}
Tommasi Junior H.L., Favaron P.O., Rodrigues R.F., Guimarães P.G. \& Miglino M.A. 2014. [Development of the integumentary system in bovine with estimated gestational ages from 20 to 140 days.] Desenvolvimento do sistema tegumentar em bovinos com idades gestacionais estimadas de 20 a 140 dias. Pesquisa Veterinária Brasileira 34(7):695-702. Departamento de Cirurgia, Faculdade de Medicina Veterinária e Zootecnia, Universidade de São Paulo, Av. Prof. Orlando Marques de Paiva 87, Cidade Universitária, São Paulo, SP 05508-900. Brazil. E-mail: miglino@usp.br

The skin is an important part of the integumentary system, which has important functions such as protection against dehydration, injury and infection, as well as present high potential of renewal. Histologically, the skin consists of two functional layers, that are morphologically distinct, the epidermis and dermis. The mammary glands, ungueal capsule and horn are also part of this system. Due the poor data available on literature about the development of skin and other cornea attachments in bovine, the aim of this study was to describe the morphological characteristics of the integumentary system development during the embryonic and fetal periods in bovine. Individuals were allocated in three groups: Group I - embryos from 20 to 26 days $(n=4)$, Group II - embryos from 30 to 47 days $(n=6)$ and Group III - fetuses from 74 to 140 days $(n=6)$. During the development of the skin it was observed different morphological patterns according to the analyzed regions. Especially, a higher level of differentiation was observed during 30-47 days of gestation. The bovine claw and mammary gland develop later between 74 to 140 days of gestation. In summary, these results related to the development of the integumentary system in bovine may help the analysis and understanding of the development of their organs, as well as the pathological disorders associated to the organogenesis.
\end{abstract}

INDEX TERMS: Integumentary system, skin, mammary gland, ungueal capsule, horn, cattle.

RESUMO.- A pele representa parte importante do sistema tegumentar, pois desempenha funções como a proteção contra desidratação, lesões e infecções, além de apresentar alto poder de renovação. Histologicamente, a pele consiste de duas camadas funcionais, morfologicamente distintas, a epiderme e a derme. As glândulas mamárias, capsula ungueal e cornos também fazem parte deste sistema. Devido

\footnotetext{
${ }^{1}$ Recebido em 8 de janeiro de 2014.

Aceito para publicação em 9 de abril de 2014.

${ }^{2}$ Departamento de Cirurgia, Programa de Pós-Graduação em de Anatomia dos Animais Domésticos e Silvestres, Faculdade de Medicina Veterinária e Zootecnia (FMVZ), Universidade de São Paulo (USP), Av. Prof. Orlando Marques de Paiva 87, Cidade Universitária, São Paulo, SP 05508-270, Brasil. *Autor para correspondência: miglino@usp.br (Profa. Dra. Maria Angelica Miglino).
}

à escassez de dados na literatura sobre o desenvolvimento da pele e dos anexos de natureza córnea em bovinos, o objetivo deste trabalho foi descrever as características morfológicas do desenvolvimento do sistema tegumentar durante os períodos embrionário e fetal em bovinos. Os indivíduos foram divididos em três grupos: Grupo I - embriões de 20-26 dias $(\mathrm{n}=4)$; Grupo II - embriões 30-47 dias $(\mathrm{n}=6)$ e Grupo III - fetos de 74-140 dias (n=6). Durante o desenvolvimento da pele observou-se diferentes padrões morfológicos de acordo com as regiões analisadas, apresentando índice maior de diferenciação no intervalo entre 30-47 dias de gestação. 0 aparelho ungueal e a glândula mamária se desenvolvem mais tardiamente entre os dias 74-140 da gestação. Em resumo, estes resultados acerca do desenvolvimento do sistema tegumentar em bovinos, poderão 
auxiliar na interpretação e compreensão da formação dos órgãos que o constituem, assim como para a compreensão de alterações patológicas associadas à organogênese.

TERMOS DE INDEXAÇÃO: Sistema tegumentar, pele, glândula mamária, capsula ungueal, corno, bovinos.

\section{INTRODUÇÃO}

A pele é um órgão complexo, formado por uma porção epitelial de origem ectodérmica, a epiderme, e uma porção conjuntiva oriunda do mesoderma subjacente, a derme. Suas funções no organismo vão desde a proteção contra desidratação, lesões e infecções, além de controle da termorregulação (Hyttel et al. 2010). Além disso, devido ao seu alto poder de renovação, é considerada uma importante fonte de células tronco e para clonagem (Campbell et al. 1996, Wilmut et al. 1997, Blanpain \& Fuchs 2009).

A pele é recoberta na sua superfície por pêlos, os quais formam uma segunda barreira de proteção para o indivíduo. Os pêlos são formados por proliferações sólidas da camada basal da epiderme. As células basais epidermais dividem-se, alongam-se e penetram na derme num ângulo oblíquo, e na sua porção terminal, esse germe de pêlo invagina-se e é preenchido por células mesenquimais, formando assim a papila dermal, que contém vasos e terminações nervosas (Hyttel et al. 2010).

As glândulas mamárias, cascos e cornos também fazem parte do sistema tegumentar dos bovinos, os quais, histologicamente consistem de duas camadas funcionais e morfologicamente distintas. A camada superficial ou epiderme é formada por diferentes estratos, desenvolvidos a partir da superfície do ectoderma (Banks 1991) e as camadas mais profundas, o cório ou derme e a subcútis, consistem de tecido conjuntivo oriundo do mesoderma (Van Amstel et al. 2001, Hyttel et al. 2010).

0 estudo tanto das glândulas quanto dos apêndices do sistema tegumentar são relevantes para a clínica de bovinos, principalmente no que se refere as suas patologias. Dessa maneira, as técnicas de diagnóstico, tratamento e prognóstico das enfermidades digitais dos bovinos são melhores aplicadas quando se conhece o desenvolvimento e a anatomia das extremidades dos membros locomotores (Meredith 1996, Mendonça et al. 2003). As úlceras de solas e abscessos são doenças crônicas e onipresentes associadas a altas perdas econômicas, entre todas as lesões de extremidade de membros (Bicalho 2009). Estudos mostram ainda que fêmeas da espécie bovina com abscessos ou laminite tendem a diminuir a produção leiteira em comparação às sadias (Warnick et al. 2001).

Süsskind-Schwendi et al. (2004) relatam o seu desenvolvimento em cães, Meyer \& Görgen (1986) em suínos, Bragulla (2003) em equinos, Bragulla et al. (2001) em felinos e Sengel \& Mauger (1976) em camundongos. De maneira geral, esse sistema também foi estudado em mamíferos por Hardy (1992) e em alguns outros vertebrados por Oliveira-Martinez (2004) enfocando os eventos moleculares envolvidos na diferenciação dos tecidos.

Devido à escassez de dados na literatura sobre o desenvolvimento da pele e dos anexos de natureza córnea e glandulares em bovinos, e levando em conta a importância que tais resultados poderão ter para o esclarecimento de eventos relacionados não apenas com o desenvolvimento de tais estruturas, mas também para uma compreensão fundamentada de alterações patológicas que podem comprometer o rendimento dos bovinos e a qualidade de seus produtos, o objetivo deste trabalho foi descrever as características morfológicas do desenvolvimento do sistema tegumentar durante os períodos embrionário e fetal em bovinos.

\section{MATERIAL E MÉTODOS}

Coleta das amostras e análise macroscópica. Foram coletados 10 embriões e 6 fetos bovinos, os quais para melhor descrição e compreensão dos resultados foram separados em 3 grupos: Grupo I - embriões de 20-26 dias (n=4); Grupo II - embriões 30-47 dias (n=6) e Grupo III - fetos de 74-140 dias (n=6) (Quadro 1). As amostras foram coletadas nos frigoríficos Frigol na cidade de Lençóis Paulista-SP e no Frigorífico Municipal da cidade de Dracena-SP. Durante a coleta, para exposição do embrião/feto, cada corno uterino foi realizada uma incisão no sentido crânio caudal da cérvix uterina em direção ao corno gestante. Os períodos gestacionais dos embriões e fetos foram estimados segundo metodologia preconizada por Evans \& Sack (1973), que se baseia na mensuração da distância do ponto maior da cabeça (crista nucal) numa extremidade e a última vértebra sacral, na extremidade oposta (Crown-Rump - CR). Para tanto, utilizou-se um paquímetro de aço inoxidável. Para o registro fotográfico e análise das características anatômicas externas dos embriões, fetos e das estruturas de interesse foi utilizada uma lupa estereoscópica (Zeiss Stemi SV6, Germany) e máquina Sony MVC - CD500. A nomenclatura das estruturas analisadas esta de acordo com a nomenclatura estabelecida pelo International Committee on Veterinary Gross Anatomical Nomenclature, International Committee on Veterinary Histological and Embryological Nomenclatura, 2005.

Microscopia de luz. Para a descrição microscópica foram coletados fragmentos da pele em diferentes regiões corpóreas: cabeça, regiões dorsal e abdominal, dos membros torácicos e pélvicos, do aparelho ungueal e glândula mamária, os quais foram processados para análise histológica. Devido à sua importância clínico-cirúrgica, atenção especial foi dada as características do desenvolvimento do casco.

Quadro 1. Dados biométricos (Crown-rump e peso) e idade estimada de embriões e fetos bovinos em diferentes períodos gestacionais

\begin{tabular}{cccc}
\hline Animal & Idade estimada (dias) & Crown-rump $(\mathrm{mm})$ & Peso $(\mathrm{g})$ \\
\hline 1 & 20 & 10,2 & 0,334 \\
2 & 23 & 10,3 & 0,374 \\
3 & 25 & 10,6 & 0,550 \\
4 & 26 & 10,8 & 0,991 \\
5 & 30 & 20,4 & 1,194 \\
6 & 35 & 30 & 4,230 \\
7 & 40 & 33,25 & 41,97 \\
8 & 45 & 36,77 & 64,40 \\
9 & 46 & 36,17 & 80,22 \\
10 & 47 & 37,30 & 85,46 \\
11 & 74 & 125 & 253,64 \\
12 & 80 & 105 & 380,43 \\
13 & 86 & 170 & 420,76 \\
14 & 90 & 190 & 600,30 \\
15 & 100 & 290 & 605,45 \\
16 & 140 & 320,5 & 692,34
\end{tabular}


As amostras foram fixadas em formaldeído $10 \%$ durante 48 horas. Após a fixação as amostras foram lavadas em tampão fosfato (PBS) para retirada do fixador. Em seguida, as mesmas foram desidratadas em uma série de etanóis em concentrações crescentes (70-100\%), seguido de diafanizacão em xilol e inclusão em paraplast (Tolosa et al. 2003).

Os blocos foram seccionados em micrótomo automático (Leica, RM2165) com espessurade $5 \mu \mathrm{m}$, corados com hematoxilina-eosina (HE) e posteriormente as lâminas foram analisadas e fotodocumentadas em microscópio (Olympus BX40, Zeiss KS400, Munich, Germany).

Microscopia eletrônica de varredura. Para a microscopia eletrônica de varredura, amostras do casco fixadas em glutaraldeído 2,5\% foram lavadas em tampão fosfato a $0,1 \mathrm{M} \mathrm{pH} 7,4$, e pós fixadas em tetróxido de ósmio a 1\%, seguido de desidratações a seco em ponto crítico (Balzers CPD 020) e colocado em um suporte metálico para revestimento em ouro ("sputtering" Emitech K550). Posteriormente as amostras foram analisadas em microscópio eletrônico (ME Leo 435 VP, Oberkochen, Germany).

\section{RESULTADOS}

\section{Características do desenvolvimento do embrião e da pele}

Os embriões bovinos do Grupo I possuíam idades variando de 20-26 dias de gestação ( $C R=10,2$ a $10,8 \mathrm{~cm}$ ). Nessa fase os embriões possuíam formato de "C" apresentando a região da cabeça pouco desenvolvida com a retina ainda sem pigmentação. Os arcos faríngeos em formação estavam presentes na região cervical. Proporcionalmente, o coração e o fígado eram grandes e ocupavam grande parte do volume das cavidades torácicas e abdominal, respectivamente. Os embriões desse grupo caracterizaram-se por possuir a pele fina e translúcida, sendo possível observar através da mesma os órgãos internos, como o coração e o fígado. Uma pequena projeção da parede na região torácica indicava o inicio do brotamento dos membros torácicos nos antímeros direito e esquerdo. A cauda era alongada, com forma cilíndrica e espessura relativamente similar ao restante do corpo do embrião (Fig.1A).

Histologicamente, a pele em desenvolvimento nessa fase não apresentou diferenças quanto as amostras coletadas das diferentes regiões corpóreas analisadas, cabeça (Fig.1B), região dorsal (Fig.1C) e abdominal (Fig.1D), sendo constituída basicamente por células mesenquimais indiferenciadas. Apenas na região dorsal notou-se o início da diferenciação em duas camadas distintas, além de uma fina camada de queratina revestindo a futura região da epiderme (Fig.1C). Vasos sanguíneos eram dispersos e pouco comuns (Fig.1B).

Embriões do Grupo II (30-47 dias de gestação) apresentaram as estruturas da região da cabeça mais desenvolvidas, sendo possível observar a retina pigmentada e a flexura cervical. 0 coração projetava-se na cavidade torácica e possuía coloração avermelhada in situ. Os brotos dos membros torácicos e pélvicos possuíam formato de remo, sem divisão dos dígitos. A pele nessa fase tornou-se mais espessa, embora ainda estivesse translúcida, na região ocupada pelos ossos frontal e temporal na cabeça e na região abdominal (Fig.1E). Especializações da pele puderam ser notadas nas regiões analisadas. Na região da cabeça embora houvesse predomínio de células mesenquimais notou-se o início da divisão em duas camadas, sendo a mais periférica de aspecto mais compacto formada por células intimamente relacionadas dando origem a epiderme, enquanto que a
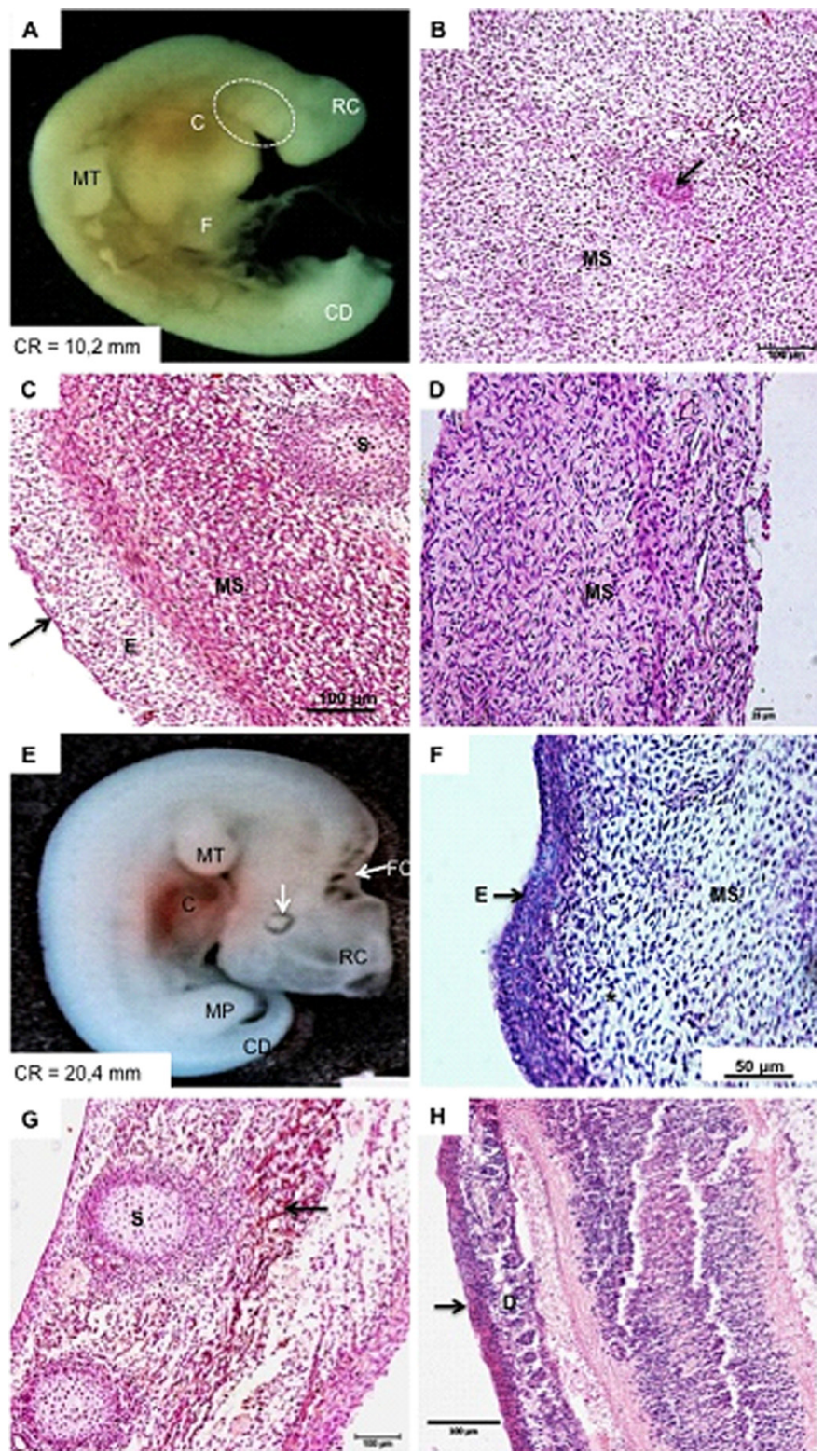

Fig.1. Desenvolvimento da pele em embriões bovinos dos Grupos I (idades estimadas de 20-26 dias) e Grupo II (30-47 dias). (A) Embrião de 20 dias. Notar a região cranial (RC), arcos faríngeos (circulo), coração (C), fígado (F), broto do membro torácico (MT) e cauda (CD). (B) Histologia da pele da região da cabeça com 20 dias formada por células mesenquimais indiferenciadas (MS) e vasos sanguíneos (seta). (C,D) Histologia da pele da região dorsal e abdominal, respectivamente aos 23 dias. Notar sua composição mesenquimal (MS), fina camada de queratina (seta) revestindo a futura epiderme (E) e somitos (S). (E) Embrião de 30 dias (Grupo II). Notar a região cranial (RC), flexura cervical (FC), retina pigmentada (seta), coração (C), brotos dos membros torácicos (MT) e pélvico (MP) e cauda (CD). (F), Epiderme (E), tecido mesenquimal subjacente (MS) e células conjuntivas $\left(^{*}\right)$ da pele da região cranial aos 30 dias. (G) Pele da região do dorso de embrião com 35 dias. Notar os somitos em formação (S) e intensa vascularização dessa região (seta). (H) Epiderme (seta) e derme (D) de embrião com 45 dias. Coloração: hematoxilina e eosina. 

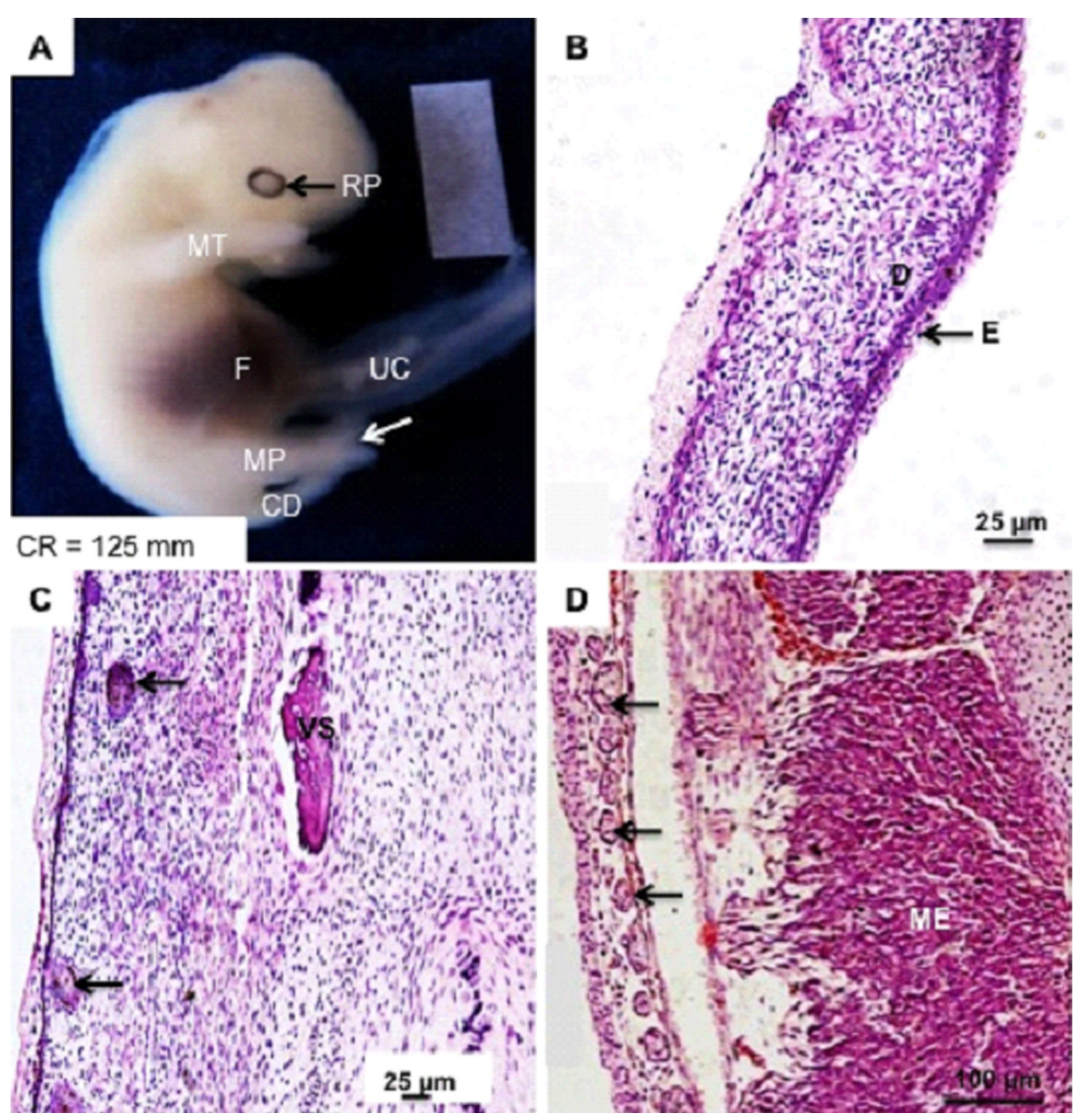

Fig.2. Desenvolvimento da pele de fetos bovinos do Grupo III com idades entre 74-140 dias de gestação. (A) Feto com 74 dias de gestação. Notar a retina pigmentada (RP) na região cranial, membro torácico (MT) e membro pélvico (MP) com dígitos divididos (seta). (B) Pele da região cranial evidenciando a epiderme (E) e derme (D) de feto bovino com 86 dias de gestação. (C) Pele da região do dorso com folículos pilosos (setas) e vasos sanguíneos (VS) de feto bovino com 86 dias. (D) Feto com 100 dias de gestação evidenciando a musculatura esquelética subjacente (ME), bem como folículos pilosos abundantes (setas). Coloração: hematoxilina e eosina.

camada seguinte possuía aspecto semelhante a tecido conjuntivo (Fig.1F). Na região dorsal notou-se a formação dos somitos,formados por aglomerados celulares. Nesse período, observou-se aumento da vascularização das camadas da pele (Fig.1G) e com o avanço da gestação os indivíduos do Grupo II apresentaram divisão da pele nas camadas epiderme e derme (Fig.1H).

No Grupo III, os fetos em estágio mais avançado de desenvolvimento apresentaram as regiões corpóreas bem definidas. De um modo geral, com o aumento da proliferação celular e espessamento da pele e consequentemente especialização de suas camadas constituintes, a mesma perde a translucidez, ficando evidente apenas a impressão do fígado na cavidade abdominal. Essa fase é caracterizada pela bifurcação dos dígitos (Fig.2A). Na região da cabeça, a pele fina está em contato íntimo com os ossos do crâ- nio. Suas camadas constituintes são a epiderme e a derme (Fig.2B). Ao longo do corpo aparecem os primeiros folículos pilosos (Fig.2C), embora os pêlos exteriorizados propriamente ditos não tenham sido observados. Tornou-se evidente a organização celular das camadas da pele com uma camada basal mais delimitada (Fig.2C). Contudo, esta diferenciação não foi igual para todas as regiões do corpo analisadas. Vasos sanguíneos que promovem a irrigação da pele também se tornaram mais evidentes e abundantes (Fig. 2C). Nos fetos com idades mais avançadas (100 dias de gestação) foi possível observar também o desenvolvimento da musculatura esquelética subjacente à pele (Fig.2D).

Em todo o período avaliado não foi observada a formação ou desenvolvimento dos cornos na região correspondente ao osso frontal. 

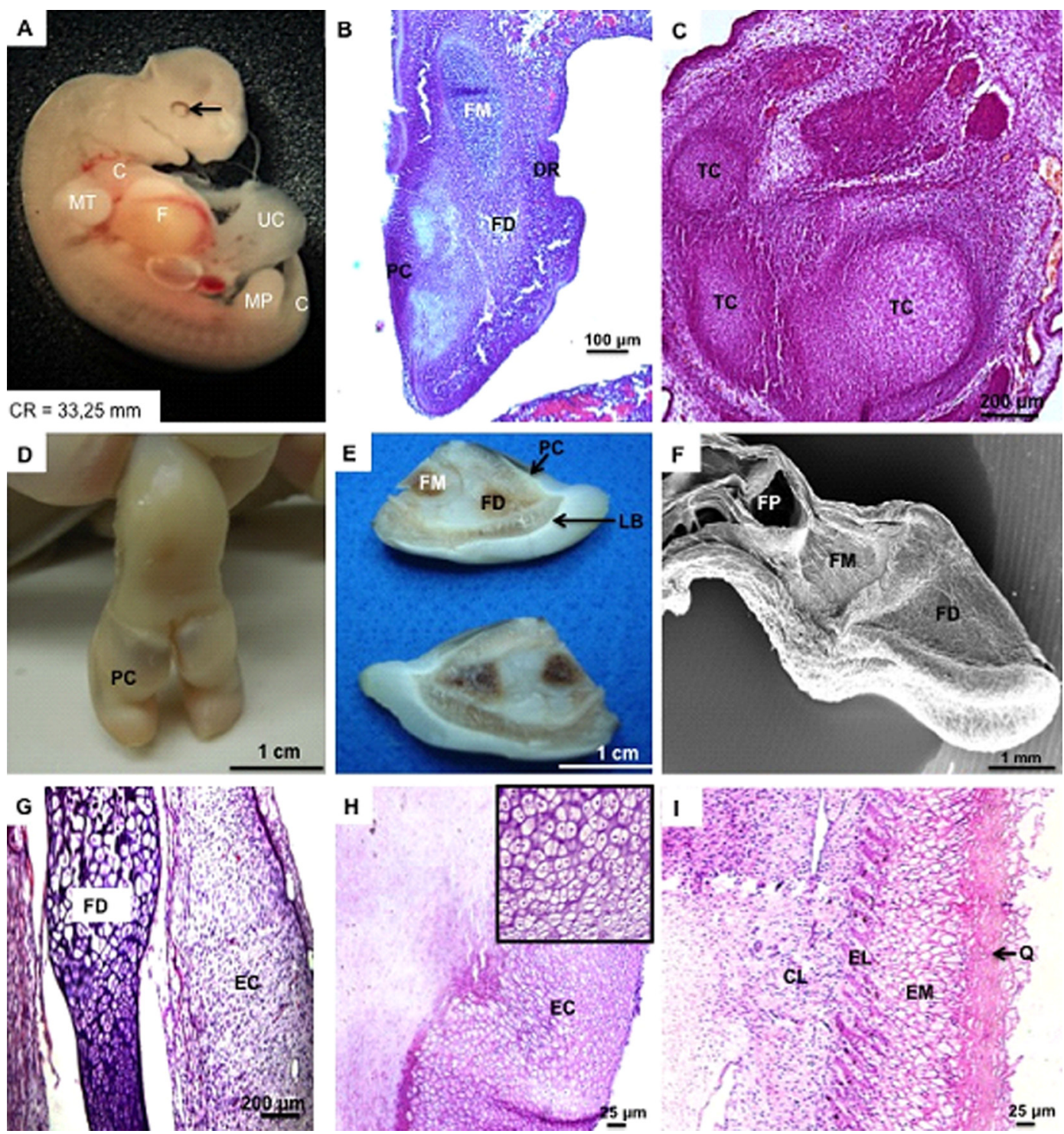

Fig.3. Desenvolvimento do aparelho ungueal de embriões (Grupo II, idades estimadas de 30-47 dias de gestação) e fetos bovinos (Grupo III, idades estimadas entre 74-140 dias). (A) Embrião de 40 dias. Notar a retina pigmentada (seta) na região craniana, coração $(\mathrm{C})$, fígado (F), cauda (C) e cordão umbilical (UC). Os brotos dos membros torácico (MT) e pélvico (MP) possuem formato de remo sem divisão dos dígitos. (B,C) Embriões de 40 e 46 dias, respectivamente. Notar a parede do casco (PC) e digito rudimentar (DR), assim como o processo de condensação do tecido cartilaginoso (TC) para formação das falanges media e distal. (D) Macroscopia da extremidade distal do membro pélvico de feto de 100 dias evidenciando a bipartição dos dígitos revestidos pela parede do casco (PC). (E,F) Corte sagital-mediano do casco de feto de 140 dias em visão macroscópica e microscopia eletrônica de varredura, respectivamente. Notar as falanges proximal (FP), media (FM) e distal (FD) ossificadas, bem como a característica cartilaginosa da parede do casco (PC) e linha branca (LB). (G,H) Histologia do casco onde notam-se condrócitos arredondados e com núcleo centralizado da epiderme coronária (EC) com 100 dias. FD = falange distal. (I) Feto com 140 dias do casco com queratinizarão do estrato tectório (Q). Notar ainda o estrato médio (EM), estrato lamelar primário (EL) e corio laminar (CL). Coloração: hematoxilina e eosina.

\section{Desenvolvimento do aparelho ungueal}

Após o surgimento dos brotos dos membros torácicos no Grupo I (Fig.1A) e pélvicos no Grupo II (Figs. 1E e 3A), com consequente divisão dos dígitos no Grupo III (Fig.2A) caracterizou-se a formação e desenvolvimento do aparelho ungueal nos fetos bovinos.

Histologicamente, nos indivíduos presentes no Grupo II (30-47 dias de gestação) observou-se condensações de tecido cartilaginoso nos brotos dos membros, torácicos e pélvicos, e desenvolvimento das zonas de cartilagem, entretanto, não foi constatada a bipartição dos membros (Fig.3B, C). Perifericamente as extremidades dos membros eram revestidas por uma fina camada formada por queratinócitos (Fig.3C).

Nos fetos (Grupo III, 74-140 dias de gestação) identificou-se a bipartição dos dígitos (segundo e terceiro), que se 
completou aos 100 dias de gestação (Fig.3D). Nessa fase, os membros pélvicos e torácicos apresentaram o aparelho ungueal bem desenvolvido, semelhante ao bovino adulto, podendo se observar as estruturas na superfície palmar e plantar, tais como a parede do casco, a sola, sulco paracuneal e linha branca (Fig.3D-F). Através de cortes sagital-medianos avaliados macroscopicamente e através de microscopia eletrônica de varredura, notou-se o inicio do processo de ossificação das falanges proximal, média e distal (Fig.3E, F). Nesses indivíduos, através de microscopia de luz evidenciou-se as zonas de ossificação do casco como a formação do extrato córneo. A epiderme e a derme estavam bem diferenciadas sendo possível observar condrócitos arredondados na epiderme coronária aos 100 dias.

Aos 140 dias, notou-se a epiderme laminar, bem como a queratinização do estrato tectório. Nesse período, foi possível diferenciar o estrato médio, estrato lamelar primário e cório laminar (Fig.3G-I).

\section{Desenvolvimento da glândula mamária}

Nos indivíduos do Grupo II, foi possível visualizar uma linha na região inguinal sugerindo o possível local de desenvolvimento das glândulas mamárias. As glândulas mamárias propriamente ditas surgiram como uma projeção formada pelo espessamento da epiderme inicialmente em posição ventrolateral na parede abdominal, porém depois se localiza na região inguinal, como observado nos indivíduos do Grupo III (Fig.4A),sendo que os primórdios dos ductos lactíferos foram observados em fetos a partir de 90 dias de gestação (Fig.4B). Através da multiplicação, agregação e diferenciação celular quatro tetas se formam. Histologicamente, identificou-se o desenvolvimento de uma região parenquimatosa constituída de células epiteliais secretoras que dão origem aos alvéolos mamários (Fig.4C).

\section{DISCUSSÃO}

Estudos relativos ao desenvolvimento embrionário têm como objetivo principal melhorar a manutenção dos conceptos em gestações oriundas não apenas de monta natural, mas também daqueles desenvolvidos a partir de técnicas de reprodução assistida, como a fertilização in vitro, inseminação artificial e clonagem (Assis Neto et al. 2009). Além de entender os padrões morfológicos de crescimento para cada estágio de desenvolvimento, afim de gerar dados que possam ser seguidos como base para o acompanhamento do correto desenvolvimento.

A idade do concepto é determinada pelas muitas características típicas morfológicas que ele apresenta (Assis Neto et al. 2010). 0 presente trabalho analisou o desenvolvimento embrionário da pele, aparelho ungueal e glândula mamária de bovinos em diferentes fases de gestação. Observamos que os primórdios, do desenvolvimento do membro torácico, ocorre em embriões de 20-26 dias de gestação (Grupo I), bem como nos embriões de 30 dias (Grupo II) onde os brotos dos membros torácicos e pélvicos começam a se desenvolver, assim como encontrado por Evans \& Sack (1973) e Alberto et al. (2013).

Apesar do grande valor econômico que os bovinos possuem, poucos são os trabalhos que relatam sobre a sua pele
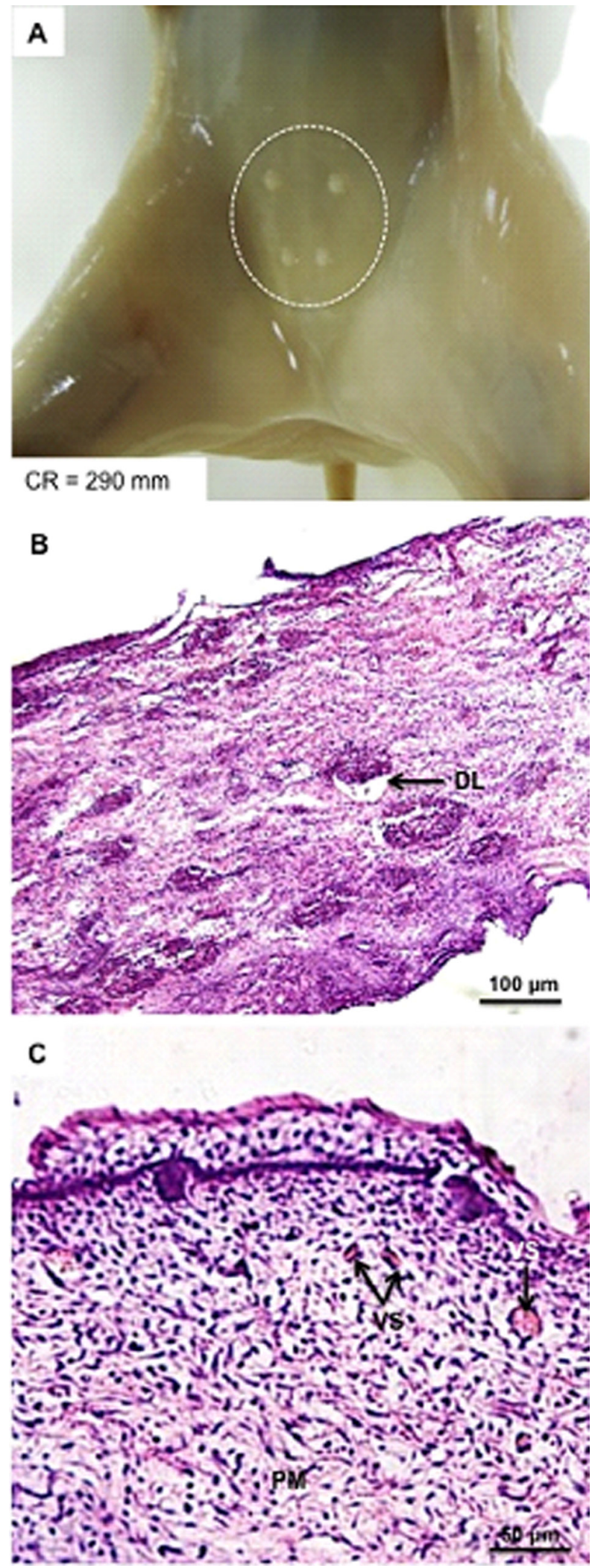

Fig.4. Desenvolvimento da glândula mamaria em fetos bovinos do Grupo III (idades estimadas entre 74-140 dias de gestação). (A) Visão macroscópica da região inguinal de feto com 100 dias. Notar a projeção e exteriorização das 4 tetas. (B,C) Cortes histológicos da região da glândula mamaria de fetos com 90 dias de gestação. Notar os ductos lactíferos (DL) e parênquima (PM) com células epiteliais e vasos sanguíneos (VS). 
e pelagem (Lyne \& Heideman 1958), sendo que os existentes são principalmente resultantes de animais adultos. Lyne \& Heideman (1958) estudando o desenvolvimento pré-natal da pele e pêlos em bovinos observaram que a espessura total da pele aumenta durante todo o desenvolvimento, havendo um aumento bem definido e subsequente diminuição da espessura da epiderme durante o período fetal. Padrão de desenvolvimento semelhante ao observado em nosso estudo. Os autores observaram ainda que a formação do folículo piloso inicia-se aos 77 dias de gestação, diferente de Winters et al. (1942) que observaram a primeira aparição de folículos pilosos em fetos bovinos de 90 dias, bem como a cobertura completa do corpo com pêlos aos 230 dias.

Os padrões de linhas de clivagem da pele foram estudados em fetos bovinos e ovinos e observou-se que existem diferenças de acordo com a região (Wakuri et al. 1986, 1994). Em nosso estudo também pudemos observar que o desenvolvimento epidermal variou de acordo com a região do corpo, sendo o primeiro a região da cabeça o mais desenvolvido (embora sem grandes especializações teciduais para a região) quando comparado às outras regiões corpóreas.

A estratificação da pele de fetos ovinos começa no $52^{\circ}$ ำ dia, sendo que no $26^{\circ}$ a epiderme era composta de uma única camada de células cubóides (Ahmed et al. 1985). No presente estudo, encontramos nas amostras analisadas, o inicio da estratificação no Grupo III, sendo que esta ainda estava no início em apenas algumas regiões do corpo dos embriões. No Grupo I, a epiderme era composta de uma única camada um pouco mais diferenciada do embrião de 23 dias de gestação, sendo que, na região da cabeça a epiderme era mais espessa. Segundo Lyne \& Heideman (1958) as alterações na pele em relação ao primeiro ciclo de pêlo em bovinos são similares aos descritos para outros animais (Chase et al. 1953, Herrmann et al. 1955), sendo que a medida que os folículos se desenvolvem a pele se torna mais espessa, devido principalmente ao aumento na espessura da derme.

Em nosso estudo, não se observou camadas de células diferentes na camada basal e a camada de queratina da epiderme é mais evidente na fase fetal. Resultados semelhantes foram encontrados por Budras et al. (1996), os quais notaram uma mudança na queratinização de fetos, onde uma grande número de células espinhosas mudou para um grupo de poucas células por unidade de área, alterando assim a taxa de queratinização de alta para baixa.

0 desenvolvimento dos vasos sanguíneos da pele de fetos bovinos é dividido em zonas vasculares, ou seja, cada unidade é centralmente suprida por um ramo arterioso cutâneo e o sangue venoso é drenado de cada unidade pelas tributárias do plexo venoso da derme profunda (El-Bab et al. 1983). Notamos que a irrigação da pele também tornou-se mais evidente e abundante durante o desenvolvimento do animais, porém não foi observado as divisões da zonas.

Estudos revelaram que feixes de axônios não mielinizados estão localizados nos vasos sanguíneos da derme no $68^{\circ}$ dia de gestação e aos 75 dias a inervação da pele é observada por mancha de prata, quando as fibras podem ser vistas ao longo dos vasos da derme (Rees et al. 1994), estruturas não identificadas em nosso estudo.

A morfologia do casco e suas anormalidades em animais adultos são bem descritos (Schivachelvan et al. 1992, Miller et al. 1986, Urgulu \& Armutak 1996Amstel et al. 2001, Karahan et al. 2007, Nuss et al. 2011), porém ainda são escassos os trabalhos que relatam o seu desenvolvimento. Em nosso estudo não foi evidenciado a queratinização de células em regiões secundárias, adjacentes às bifurcações da lâmina córnea como foi localizado em alguns casos em equinos (Budras et al. 1989).

Em todos os mamíferos as glândulas mamárias surgem a partir de um espessamento localizado na ectoderme (Hovey et al. 2002). Segundo Cunha \& Hom (1996), o desenvolvimento fetal do epitélio da glândula mamária é fortemente influenciado pelo mesênquima ao seu redor. Somente foram observadas as glândulas mamárias em fetos (Grupo III), as quais apresentaram uma homogeneidade de suas células com o parênquima um pouco mais diferenciado com ductos ainda em desenvolvimento. Na fase anterior (Grupo II, 30-47 dias de gestação), uma linha na região inguinal foi observada, sugerindo a localização de desenvolvimento das glândulas mamárias. No feto bovino, quatro papilas mamárias, dão origem a quatro glândulas do úbere e aparecem pela primeira vez quando o feto tem entre 4-8 $\mathrm{cm}$. 0 cordão mamário fica canalizado para formar o canal estriado e cisterna na fase de $19 \mathrm{~cm}$ enquanto os ramos secundários surgem a partir da cisterna dilatada na fase de 16-23cm (Raynaud 1961).

Durante o desenvolvimento pós-natal o estroma se constitui de uma matriz de tecido conjuntivo e adiposo, conhecidos com almofada de gordura mamária (Neville et al. 1998). No feto bovino a almofada de gordura mamária torna-se aparentemente por volta do $80^{\circ}$ dia de gestação. Este tecido adiposo, não foi observado em nossas amostras e pouco é sabido sobre o seu desenvolvimento posterior em ruminante (Sheffield 1988).

Esta almofada de gordura e seus diversos constituintes facilitam muitas funções da glândula, abriga um sistema vascular e linfático, fornece uma matriz tridimensional e membrana basal, e funciona como um sítio local para a ação hormonal, o fornecimento de lipídios e síntese do fator de crescimento (Hovey et al. 1999).

Este trabalho é de grande importância para o conhecimento da biologia do desenvolvimento de embriões e fetos bovinos, podendo desta forma auxiliar em alterações ocorridas durante a utilização de diferentes técnicas de reprodução, uma vez que estas estão cada vez mais avançadas.

\section{CONCLUSÕES}

Podemos concluir que a pele, durante o desenvolvimento embriológico apresenta diferentes padrões de desenvolvimento de acordo com a região analisada com índice maior de diferenciação no intervalo de 30-47 dias de gestação.

Por outro lado, o aparelho ungueal desenvolve-se mais tardiamente nos dias 74-140 da gestação. Os dados morfológicos aqui apresentados contribuem não apenas para a compreensão do desenvolvimento normal, mas também 
das alterações patológicas que podem ocorrer durante o desenvolvimento da pele e outros anexos córneos em bovinos.

\section{REFERÊNCIAS}

Ahmed M.A.A., Schwarz R. \& El-Bab F.R.M. 1985. Micromorphological Studies on the epidermis, hair follicles and skin glands of sheep during prenatal life. Assiut Vet. Med. J. 14:21-30.

Alberto M.L.V., Meirelles F.V., Perecin F., Ambrósio C.E., Favaron P.O., Franciolli A.L.R., Mess A.M., Santos J.M., Rici R.E.G., Bertolini M. \& Miglino M.A. 2013. Development of bovine embryos derived from reproductive techniques. Reprod. Fertil. Develop. 25:907-917. <http://dx.doi. org/10.1071/RD12092>

Assis Neto A.C., Morceli J.A.B., Fonseca R., Ambrósio C.E., Pereira F.T.V. \& Miglino M.A. 2009. Evolução morfométrica dos anexos embrionários e fetais bovinos obtidos por monta natural, com 10 a 70 dias da gestação. Pesq. Vet. Bras. 29:859-862.

Assis Neto A.C., Pereira F.T.V., Santos T.C., Ambrósio C.E., Leiser R. \& Miglino M.A. 2010. Morpho-physical recording of bovine conceptus (Bos indicus) and placenta from days 20 to 70 of pregnancy. Reprod. Domest. Anim. 45:760-772.

Banks J.W. 1991. Tratado de Histologia Veterinária. 2ª ed. Editora Guanabara, São Paulo, p.391-392.

Blanpain C. \& Fuchs E. 2009. Epidermal homeostasis: a balancing act of stem cells in the skin. Natl Rev. Mol. Cell. Biol. 10:207-217.

Bragulla H., Ernsberger S. \& Budras K.D. 2001. On the development of the papillary body in the feline claw. Anat. Histol. Embriol. 4:211-217.

Bragulla H. 2003. Fetal development of the segment-specific papillary body in the equine hoof. J. Morphol. 258:207-224.

Budras K.D., Mülling C. \& Horowitz A. 1996. Rate of keratinization of the wall segment of the hoof and its relation to width and structure of the zona alba (white line) with respect to claw disease in cattle. Am. J. Vet. Res. 57:444-455.

Budras D.K., Hullinger L.R. \& Sack O.W. 1989. Light and electron microscopy of keratinization in the laminar epidermis of the equine hoof with reference to laminitis. Am. J. Vet. Res. 50:1150-1159.

Campbell K.H., McWhir J., Ritchie W.A. \& Wilmut I. 1996. Sheep cloned by nuclear transfer from a cultured cell line. Nature. 380:64-66.

Chase H.B., Montagna W. \& Malone J.D. 1953. Changes in the skin in relation to the hair growth cycle. Anat. Rec. 116:75-82.

Cunha G.R. \& Hom Y.K. 1996. Role of mesenchymal-one. Int. J. Cancer 51:416-424.

El-Bab F.R.M., Schawrz R. \& Godynicki S. 1983. The morphogenesis of the vasculature in bovine fetal skin. J. Anat. 136(3):561-572.

Evans H.E. \& Sack W.O. 1973. Prenatal development of domestic and laboratory mammals: growth curves, external features and selected references. Zentralbl. Veterinärmed. C 2:11-45.

Hardy M.H. 1992. The secret life of the hair follicle. Trends in Genetics 2:55-61.

Herrmann F., Morrill S.D., Sherwin R.W., Rothstein M.J. \& Sulzberger MB. 1955. Factors influencing the incidence of epidermal methylcholanthrene tumors in mice treated with cortisone. III. Studies of the hair follicular cycle ("skin cycle") in relation to the incidence of tumors after cortisone administration. J. Invest Dermatol. 25:423-38.

Hovey R.C., McFadden T.B. \& Akers R.M. 1999. Regulation of mammary gland growth and morphogenesis by the mammary fat pad: a species comparison. J. Mammary Gland Biology and Neoplasia 4:53-68.

Hovey R.C., Trott J.F. \& Von der Haar B.K. 2002. Establishing a framework for the Functional Mammary Gland: From Endocrinology to Morphology. J. Mammary Gland Biology and Neoplasia 7:17-38.

Hyttel P., Sinowatz F. \& Vejisted M. 2010. The integumentary system, p.317-329. In: Ibid. (Eds), Essentials of Domestic Animals Embryology. Saunders Elsevier, China.

International Committee on Veterinary Gross Anatomical Nomenclatura. 2005. Nomina Anatomica Veterinaria. $5^{\text {th }}$ ed. Nomina Histológica $\left(2^{\text {nd }}\right.$ ed.) and Nomina Embriologica Veterinaria. Editorial Committee Hannover, Columbia. 166p.

Karahan S., Yildz D. \& Bolat D. 2007. Scanning Electron Microscopic features of the ovine interdigital Sinus. Acta Vet. Hungar. 55:417-424.

Sheffield L.G. 1988. Organization and growth of mammary epithelia in the mammary gland fat pad. J. Dairy Sci. 71:2855-2874.

Lyne A.G. \& Heideman M.M. 1959. The pre-natal development of skin and hair in cattle (Bos taurus L.). Aust. J. Biol. Sci. 12:72-85.

Mendonça A.C., Franco da Silva L.A., Fioravanti M.C.S., Moraes J.O.R., Almeida C.F., Oliveira K.S., Oliveira M.P. \& Silva L.M. 2003. Aspectos morfológicos dos dígitos de bovinos das raças gir e holandesa. Ciênc. Anim. Bras. 4:53-60.

Meredith L.M. 1996. Clinical application of the bovine distal limb anatomy. Agri-Practice, New York, 17:93-108.

Meyer W., Görgen S. \& Schelsinger C. 1986. Structural and histochemical aspects of epidermis development of fetal porcine skin. Am. J. Anat. 2:207-219.

Nuss K., Louis S.C. \& Sigmund B. 2011. Measurements of forelimb claw dimensions in cows using a standardised sole thickness: a post- mortem study. Vet. Journal 190:84-89.

Oliveira-Martinez I., Theleu J. \& Dhoualliy D. 2004. Molecular mechanisms controlling dorsal dermis generation from the somitic dermomyotome. Int. J. Development 48:93-101.

Raynaud A. 1961. Morphogenesis of the mammary gland, p.3-46. In: Kon S.K. \& Cowie A.T. (Eds), Milk: the mammary gland and its secretions. Academic Press, New York.

Rees S., Nitsos I. \& Rawson J. 1994. The development of cuttaneous afferent pathways in fetal sheep: a structural and functional study. Brain Res. 661:207-222.

Süsskind-Schwendi M.V., Bragulla H. \& Hirschberg R.M. 2005. The prenatal development of the canine claw. Anat. Histol. Embryol. 34. DOI: 10.1111/j.1439-0264.2005.00669_116.x

Sengel P. \& Mauger A. 1976. Peridermal cell patterning in the featherforming skin of the chick embryo. Developmental Biology 51:166-171.

Tolosa E.M.C., Rodrigues C.J., Behemer O.A. \& Freitas-Neto A.G. 2003. Manual de Técnicas para Histologia Normal e Patológica. Manole, São Paulo, p.341.

Van Amstel S. \& Shearer J.K. 2001. Abnormalites of hoof growth and development. Vet. Clin. North Am., Food Anim. Pract. 17:73-91.

Wakuri H. \& Kirk E. 1994. Development of cleavage line patterns in the skin of the ovine fetus. Okajimas Folia Anatomica Japan 71:143-169.

Wakuri H., Muthou K.I. \& Miyajima T. 1986. Cleavage line patterns of the skin in bovine fetuses. Kitasato Archs Exp. Med. 59:9-20.

Warnick L.D., Janssen D., Guard C.L. \& Gröhn Y.T. 2001. The effect of lameness on milk production in dairy cows. J. Dairy Sci. 84:1988-1997.

Wilmut I., Schnieke A.E., McWhir J., Kind A.J. \& Campbell K.H. 1997. Viable offspring derived from fetal and adult mammalian cells. Nature. 385:810-3.

Winters L.M., Green W.W. \& Comstock R.E. 1942. Prenatal development of the bovine. Techn. Bull. 151, Univ. Agric. Exp. Sta. Minnesota, p.3-50. 